\title{
Arbor
}

\section{Hasta los últimos confines}

\author{
Joaquín $M^{a}$ Córdoba
}

Arbor CLXXX, 711-712 (Marzo-Abril 2005), 747-755 pp.

El 19 de mayo de 1798, la flota encargada de trasladar el ejército que iba a conquistar Egipto levó anclas del puerto de Toulon. Aunque tres años después la aventura se saldara en fracaso, el siglo XIX comenzó así con este temprano intento francés, que consiguió dominar durante algún tiempo el Valle del Nilo, soñó abrir el Canal de Suez y decidió el desarrollo moderno de los estudios sobre la cultura islámica y el antiguo Egipto ${ }^{1}$. Desde entonces y hasta la I Guerra Mundial, el mundo iba a vivir la incesante expansión europea, particularmente la de sus grandes estados como Inglaterra, Francia, Alemania y Rusia, cuyos viajeros, exploradores, colonos y ejércitos llegarían a todos los rincones del mundo y, por supuesto, a todos los de Oriente, desde los desiertos de Arabia hasta los confines del Pamir y las arenas del Taklamakán. Pero lo paradójico es que a pesar de la debilidad y posición marginal de España en la Europa de su tiempo, viajeros españoles llevados las más de las veces de su sólo valor y esfuerzo, alcanzaron también los últimos confines de Oriente, desde La Meca en Arabia hasta el Desierto Salino de Irán o las montañas de Anatolia, dejando valiosa memoria escrita de sus aventuras.

En la historia del viaje, aquel siglo empezó bien para España. Mientras Napoleón Bonaparte actuaba como cónsul vitalicio y se coronaba emperador en 1804, un extraordinario viajero y aventurero español llamado Domingo Badía y Leblich, tras residir en Marruecos durante años cruzaba el norte de África, desembarcaba en Egipto, navegaba por el Mar Rojo y peregrinaba a La Meca, desde donde por Siria y Turquía volvió a Europa. La publicación de su libro, sus mapas y sus dibujos revelarían por vez primera regiones hasta entonces desconocidas, convirtiéndole a él mismo en la leyenda que los malévolos comentarios de Johann Ludwig Burckhardt, viajero y también peregrino a La Meca en 1814, no conseguiría destruir ${ }^{2}$. 
Pese a tan prometedor comienzo, por aquellos años nuestro país se hundió en las consecuencias de la Guerra de la Independencia y las luchas entre liberales y absolutistas, quedando postrado y lejos de la experiencia oriental hasta la época de Prim y la Restauración. Pero del resto de Europa, con la paz surgida del Congreso de Viena y el equilibrio mantenido por Metternich (1815-1848), multitud de viajeros partirían hacia Oriente a la búsqueda de un mito, al tiempo que su fascinación se exacerbaba con el Romanticismo y el Liberalismo en la literatura, el arte y la música. Una temprana experiencia "orientalista» vendría de la pluma de Chateaubriand, cuyo Itinéraire de Paris à Jerusalem (1811) inauguraría un nuevo género ${ }^{3}$. No mucho después, entre las primeras aproximaciones literarias se contaría la de Goethe, que apasionado por las traducciones de Joseph von Hammer-Purgstall sobre la lírica del poeta Hafiz, encontraría una original inspiración vertida en los poemas del Westöstliche Divan (1819) ${ }^{4}$. Y en fin, el 3 de febrero de 1823 sonarían en La Fenice veneciana los compases de una ópera típica del estilo de Rossini, Semiramide, una de las varias que el músico adorado por Stendhal dedicara a Oriente ${ }^{5}$.

En aquella época precisa, tres ingleses singulares coincidieron en $\mathrm{Me}$ sopotamia: Claudius James Rich, James S. Buckingham y Robert Ker Porter. El primero, cónsul británico en Bagdad (1808-1821), realizó estudios y viajes por toda la región, reuniendo una colección de antigüedades que su viuda legaría al Museo Británico ${ }^{6}$. Sus consejos y ayuda serían decisivos en el viaje de J. S Buckingham -noble que en 1816 pasó por Bagdad en ruta hacia la India, siguiendo un típico y nuevo "grand tour» ${ }^{7}$, , y en el del artista y romántico aventurero Robert Ker Porter, que al servicio de Rusia llevó a cabo un original viaje por Irán y Mesopotamia, trazando unas bellas y rigurosas acuarelas de monumentos y ruinas, verdaderas instántaneas tomadas según las instrucciones dadas por el primo de su esposa, A. Olinen, presidente de la Academia Rusa de las Bellas Artes ${ }^{8}$. Pero ellos fueron sólo tres de los muchos viajeros británicos de vocación u obligación, que en aquellas décadas en las que Gran Bretaña actuaba sin competidores en el Oriente Próximo o Lejano, pasaron por Iraq e Irán camino de la India. Los cementerios cristianos de ambos países todavía hoy testimonian el recuerdo de los muchos que nunca volvieron $^{9}$. Pero en muy poco tiempo, la situación iba a cambiar.

En 1830, la Revolución de Julio llevó al trono a Luis Felipe (18301848), bajo cuyo gobierno se alzó al poder la burguesía, se aceleró el desarrollo industrial y se intentó la expansión colonial y política reanudando la competencia con Gran Bretaña. Entre aquel año y el comienzo 


\section{Hasta los últimos confines}

de la Guerra de Crimea (1854-1856), los aventureros franceses volvieron al corazón del Oriente, al tiempo que las primeras excavaciones arqueológicas deparaban al descubrimiento de las grandes capitales asirias ${ }^{10}$. Fue también ésta la época dorada de los "pintores viajeros»" ${ }^{11}$, que llevarían a los gabinetes y salones europeos tipos y paisajes orientales llenos de luz y colorido, vertido en brillantes escenas de jinetes, poblados, tiendas y desiertos, o en interiores domésticos y escenas de baños y harenes, en los que fue acentuándose poco a poco un erotismo morboso. Entonces fue la hora de Prosper Marilhat y sus paisajes restallantes de sol, de David Roberts y sus espléndidas ruinas remotas, de John Frederick Lewis y sus interiores de luz tamizada, de Jules Laurens y sus impresionantes vistas del norte de Anatolia e Irán, de Théodore Frère y sus beduinos bajo un azul inacabable y, un poco más tarde, de Jean-Léon Gérôme y sus bailarinas, baños femeninos, zocos y gentes del pueblo ${ }^{12}$. Pues bien, por sendas iguales que las de los pintores caminaron el viajero y arqueólogo Charles Félix Marie Texier (1833-36 y 1839), y poco después el equipo formado por el arquitecto Pascal Coste y el pintor Eugène Fladin. Texier llevó a cabo exploraciones por Asia Menor -descubriendo la vieja capital de los hititas, donde trazó planos y dibujos sorprendentes-, Irán, Armenia y Mesopotamia ${ }^{13}$,que le granjearon gran reputación. Pero Coste y Flandin alcanzarían mayor fama. Arquitecto riguroso el primero, artista por él formado en el dibujo de arquitectura el segundo, ambos tomaron parte en la embajada del conde Ernest de Sercey, enviada por orden de Luis Felipe a Teherán en 1839. Su misión era levantar planos y dibujos de todos los monumentos de Irán, y tras la vuelta del embajador, los dos se quedaron en el país, recorriéndolo en todas direcciones. Además de las maravillosas láminas que ilustraban con fidelidad absoluta el aspecto y estado de las antiguas ruinas de Persépolis, Naqs-i Rustám, Firuzabad o Bishapur, ambos firmaron a su vuelta un interesante libro de viaje, lleno de observaciones curiosas ${ }^{14}$. Mientras dibujaba en Behistun los relieves de Darío, Flandin recibió la visita de un joven inglés que, camino de la India, había preferido dedicarse a conocer gentes y paisajes de Irán e Iraq. En breve, aquel aventurero sería el competidor británico de los hallazgos franceses en Asiria. Se llamaba A. H. Layard ${ }^{15}$.

Y es que muy poco después, la competencia política y comercial franco-británica saltó a la ciencia, la cultura y los museos nacionales. Los grandes descubrimientos de P. E. Botta y V. Place en Jorsabad (18431844 y 1852-1854) y los de A. H. Layard en Nimrud y Nínive (1845-1847 y 1849-1851) traerían a Europa la imagen y la realidad histórica de un Oriente antiguo y fastuoso, convirtiendo a los museos del Louvre y Britá- 
nico, con los magníficos relieves y esculturas de sus recién inauguradas salas de Asiria, en orgullosos exponentes de la grandeza imperial de sus naciones ${ }^{16}$. Por aquel entonces, los aficionados a la ópera tarareaban con fruición los famosos coros del Nabucco de Verdi, estrenado el 9 de marzo de 1842 en la Scala de Milán. Aunque su libreto estuviera inspirado en los textos bíblicos y las leyendas posteriores todavía, el Nabucodonosor de Verdi se paseaba en escena por los Jardines Colgantes de Babilonia, y su figura era salvada en último extremo ${ }^{17}$. Pinturas, láminas y hallazgos dominaban ya la visión orientalista, cuando el novelista Gustave Flaubert y su amigo Maxime Du Camp viajaron por Oriente (1849-1851), más como perezosos paseantes que como curiosos del pasado. La lectura de los recuerdos de Flaubert no deja de sorprender, aunque sin duda su visión de las danzas de las almeas y sus experiencias eróticas alimentaran luego la poderosa evocación de Salambón ${ }^{18}$. Un año después, el capitán Richard F. Burton viajaba por Arabia y entraba en La Meca, tras los pasos del español Domingo Badía - a quien admiraba-y de J. L. Burkhardt, dejando luego un libro excelente, lleno de la erudición que gustaba mostrar ${ }^{19}$. Pero la figura de Burton nos acerca a los prolegómenos de la Guerra de Crimea y a la disputa anglo-rusa por el dominio del Asia Central, un episodio más en la historia del viaje a Oriente.

A mediados del siglo XIX, la Inglaterra victoriana trataba de ampliar su imperio de la India, condicionando la política de Irán, intentado dominar Afganistán y asomándose al Asia Central, donde había de chocar con los intereses rusos. El apoyo a Turquía no tenía otra intención que salvaguardar su influencia sobre el Sultán y su imperio -en lo que coincidía con Francia-, y mantener al Imperio Ruso lejos del Oriente que ansiaban tutelar. Por eso, la victoria naval rusa de Sinope en 1853 decidió la Guerra de Crimea (1854-1856), perdida por Rusia, aunque el nuevo zar Alejandro II (1855-1881) estaba resuelto a ganarles la mano a los ingleses en Asia Central. Y lo consiguió. Dos hechos decisivos -la ocupación de Tashkent en 1865 y la de Samarcanda en 1868- se hicieron bajo su mandato, y al tiempo que se colonizaba se emprendieron multitud de viajes geográficos, y estudiosos de todo tipo comenzaron a ocuparse del pasado del Asia Central ${ }^{20}$ y Oriente. No pocos artistas, como Vasili Vereschaguin con su gran serie dedicada al Turkestán, pintaron sus paisajes, el rutilante azul de su cielo y las fantásticas cúpulas de sus madrasas y mausoleos ${ }^{21}$, y músicos como Rimsky Korsakov evocaron la emocionante leyenda de amor y heroísmo del guerrero Antar en su Segunda Sinfonía $^{22}$. En todo caso los ingleses sintieron la expansión rusa como un peligro, sentimiento reforzado por la manía rusófoba de la reina Victoria, 


\section{Hasta los últimos confines}

señalada por el mismo P. Hopkirk. Pero la pugna entre ambos imperios se mantuvo casi siempre en la zona de sombra preferida por los servicios secretos, aunque fuera rica en tipos y episodios novelescos por una y por otra parte ${ }^{23}$. Más conocidos serían los viajeros que buscaron en el Asia Central las huellas de la "Ruta de la Seda", los restos de los antiguos imperios o, simplemente, la geografía y los paisajes de espacios infinitos, en la misma época en la que Alexander Borodin estrenaba en San Petersburgo su evocador poema sinfónico En las estepas del Asia Central ${ }^{24}$. Pues bien, entre la enorme cantidad de estos viajeros y exploradores, herederos en parte de Ruy González de Clavijo y de fray Guillermo de Rubruck, ${ }^{25}$ es obligado recordar al ruso Nicolai Prjevalski, militar y cartógrafo, botánico y naturalista, autor de cuatro grandes expediciones por los rincones más remotos ${ }^{26}$ y al sueco Sven Heddin, que atravesó el desierto de Taklamakán ${ }^{27}$.

Pero tornando al Oriente más cercano, los años sesenta y setenta marcaron la vuelta de los viajeros españoles a sus pistas y a sus desiertos. La "Guerra de África» animó el interés literario, artístico y viajero del país por Marruecos y el continente africano, donde cabía la posibilidad de adquirir colonias. Era la época de las sociedades geográficas y africanistas ${ }^{28}$, y de participación española en las aventuras francesas de México e Indochina. Y durante esas décadas, diplomáticos nuestros como Antonio Bernal de O'Reilly o Adolfo de Mentaberry viajaron por Siria, Palestina o Líbano, escribiendo luego interesantes libros de viaje. Y sobre todo fue la época del gigante Adolfo Rivadeneyra, viajero por el Golfo Pérsico, Mesopotamia, Siria e Irán, y autor de dos excelentes obras que honran nuestra literatura viajera del ochocientos. Entonces incluso, un gobierno español llegó a despachar en 1871 la famosa fragata Arapiles, que transportaba a una misión científica encargada de recopilar datos y materiales para nuestro Museo Arqueológico Nacional, aunque sea obligado recordar que ni con los materiales conseguidos ni con los datos aportados, el viaje oficial pudo igualar lo que nuestra historia debe a la sola figura de Adolfo Rivadeneyra. O a lo conseguido por el valiente Víctor Abargues de Sostén, que en 1880 exploró las costas del Mar Rojo y Etiopía, donde encontró la tumba del capitán Cristobal de Gama y con ella, unió su aventura a la titánica centuria de las navegaciones y naufragios portugueses de la ruta a la India.

El siglo empezaba a morir cuando un matrimonio francés, formado por el ingeniero Marcel Dieulafoy y su esposa Jane, emprendió un largo vaje por Irán (1880-1881), tomando fotos y láminas de los rincones a los que no habían llegado P. Coste o E. Flandin. Tres años después comen- 
zarían ambos también la excavación de Susa (1884-1886), de donde trajeron al Louvre monumentos asombrosos ${ }^{29}$. Para entonces, los alemanes empezaban a hacerse sentir por Oriente, iniciando unas relaciones estrechas con Turquía. Por las rutas anatolias de Texier cabalgaron Friedrich Sarre y sus compañeros en $1895^{30}$, y por poco sus pasos no llegaron a cruzarse con los de otro español singular, el naturalista Manuel Martínez de la Escalera, que en 1898 exploró los montes y valles de Anatolia y la región del Éufrates, y que al año siguiente andaría por las montañas de Irán, pasando por los valles de los belicosos bakhtyari, hospitalarios con A. H. Layard hacía cinco décadas, y con los que el español supo entenderse bien.

Acababa el siglo y el mito de Oriente se iba desvaneciendo. El desarrollo industrial y el poderío de los ejércitos europeos dejaba en evidencia el retraso e impotencia del Imperio Otomano ${ }^{31}$; lo que antes era exótico parecía ahora inferior, y de los viejos perfumes apenas si quedaba el erotismo inventado por la pintura de ensoñación orientalista, con la exaltada sensualidad de la Salambó de Adrien Tanoux, o la Salomé de Pierre Bonnaud ${ }^{32}$. El viaje del káiser Guillermo II a Oriente, en 1898, significaba la entrada de Alemania en el juego de Oriente, e Inglaterra empezó a trazar sus redes. La poesía se iba a convertir en prosa, prosa de informes confidenciales. Y el verdadero "voyage en Orient» iba a fenecer. Pero antes, viajeros y agentes de los gobiernos, diplomáticos y arqueólogos europeos habían llegado hasta los últimos confines, y sus contemporáneos españoles habían también compartido aquella aventura.

\section{Notas}

\footnotetext{
1 Para una muy amena pero rigurosa exposición sobre la expedición francesa a Egipto, con apéndices valiosos y noticias biográficas de sus miembros, consúltese SOLÉ, R. (2001) : La expedición de Bonaparte. El nacimiento de la Egiptología. Edhasa, Barcelona.

2 El famoso viajero suizo J. L. Burckhardt, que entre 1809 y 1817 residió en Oriente, preparándose para una expedición al corazón de África, realizó en varias ocasiones comentarios despectivos sobre Domingo Badía, sus conocimientos y su viaje. Motivados sin duda por una especie de celos, su injusticia sería luego puesta de relieve por Richard F. Burton. Sobre el viaje de Burckhardt a Arabia, véase BIDwELL, R. (1976): Travellers in Arabia. The Hamlyn Publishing Group Limited, London, pp. 50-59. Y también la edición (1991): Vida y viajes de John Lewis Burckhardt. Laertes, S. A. de Ediciones, Barcelona.

3 Una temprana traducción española, debida a Pedro María de Olavide y publicada en 1828, ha sido reeditada recientemente: Chateaubriand, F. R. (2005): De París a Jerusalén. Ediciones del Viento, S. L., La Coruña.
} 


\section{Hasta los últimos confines}

${ }^{4}$ MARTini, F. (1964) : Historia de la literatura alemana. Editorial Labor, S. A., Barcelona, pp. 259-261. También en Sievernich, G. y BudDE, H. (eds.) (1989) : Europa und der Orient, 800-1900. Bertelsmann Lexikon Verlag, Berlin, p. 789.

5 Rossini dedicó varias de sus óperas a evocar Oriente, su historia o sus leyendas. La primera Ciro en Babilonia (1812), que es al tiempo ópera y oratorio: la segunda, Il turco in Italia, drama bufo más cerca de Così fan tutte que del Rapto del Serrallo, contra lo que podría parecer, y la tercera esta Semiramide. Sobre Rosini y sus obras VITOUX, F. (1989): Rossini. Alianza Editorial, S. A., Madrid. También sobre Il turco en Italia, especialmente, BATTA, A. y NEEF, S. (eds.) (1999): Ópera. Compositores, obras, intérpretes. Könemann Verlagsgesellchaft mbH, Colonia, p. 569.

6 La figura de Cl. J. Rich está más ligada a los orígenes de la arqueología en Oriente que al viaje mismo, aunque uno de los que hizo, cuyo relato sería editado póstumamente, se cuente entre los más interesantes del siglo: RICH, Cl. J. (1836) : Narrative of a Residence in Koordistan and on the Site of Ancient Nineveh. James Duncan, London. Sobre su vida es imprescindible la biografía escrita por su descendiente ALEXANDER, C. M. (1928) : Baghdad in Bygone Days. John Murray, London. Y sobre sus aportaciones a la historia del desarrollo de una arqueología en Oriente Próximo, CóRDOBA, J. Ma: (1999): "Una tumba en Isfahan. Claudius James Rich y los orígenes de la arqueología en Oriente", Isimu 2, pp. 47-71.

7 Como escribe H. McCall, el noble viajero sería capaz de incluir después en su relato escrito, toda la información hasta entonces publicada sobre el área. Véase, McCALL, H.: (1998) : "Rediscovery and Aftermath", en DALLEY, S. (ed): The Legacy of Mesopotamia. Oxford University Press, Oxford, pp. 183-213. Vid. p. 193. J. S. Buckingham publicaría sus Travels in Mesopotamia (1827) y otro libro más titulado Travels in Assyria, Media and Persia (1829).

${ }^{8}$ Sobre la vida y la obra de Robert Ker Porter es del mayor interés el trabajo de BARNETT, R. D. (1972) : «Sir Robert Ker Porter - Regency Artist and Travellem, Iran, 10, pp. 19-24 y láminas I a XII. Su libro de viaje se editaría en Londres en 1821-22, con el título Travels in Georgia, Asia, Armenia, Ancient Babylonia, during the years 1817, 1818, 1819 and 1820.

9 Muy sugerente resulta el artículo de WRIGHT, D. (1998) : «Burials and Memorials of the British in Persia", Iran, 36, pp. 165-173. Los cementerios de las comunidades armenias fueron los primeros en recibir los cuerpos de los europeos muertos por aquellas tierras. El mismo Rich recibiría definitiva sepultura en el cementerio de Isfahan. La gran cantidad de británicos contabilizados es muestra de su continuo movimiento por las rutas de Oriente durante el siglo XIX.

10 LARSEN, M. T. (1996) : The Conquest of Assyria. Excavations in an Antique Land. Routledge, London. Sigue siendo súmamente útil y preciso el clásico libro de PARROT, A. (1946): Archéologie mésopotamienne. Les étapes. Éditions Albin Michel, Paris.

11 Peltre, Ch. (1995): L'atelier du voyage. Les peintres en Orient au XIXe siècle. Éditions Gallimard, Paris.

$\widetilde{12}$ Thornton, L. (1983) : Les orientalistes peintres voyageurs 1828-1908. ACR Édition Internationale, Courbevoie (Paris): P. Marilhat, pp. 34-37, D. Roberts, pp. 60-65, J. F. Lewis, pp. 68-73, J. Laurens, pp. 80-83, Th. Frère, pp. 52-57, J.-L. Gerôme, pp. 112121. Igualmente, sobre las láminas y el viaje de D. Roberts véase, RoBERTs, D. (1990): Terre Sainte. Lithographies et journal. CELIV. Sobre J.-L. Gerôme, véase Ackerman, G. M. (1992): Jean-Léon Gerôme. ACR Éditon Internationale, Courbevoie (Paris). El tema femenino en la pintura orientalista es abordado en ThoRnToN, L. (1989): La femme dans la peinture orientaliste, ACR Édition Internationale, Courbevoie (Paris). 
${ }^{13}$ Ch. F. M. Texier publicaría varios volúmenes como resultado de sus viajes. El primero llevaría por título Description de l'Asie Mineure, Paris, 1838-1848, en 3 vols.: el segundo, L'Armenie, la Perse et la Mésoptamie, Paris 1843-1848, 2 vols. Estan obras son un nuevo tipo de literatura de viajes, más interesado por las antigüedades y las ruinas. Se trata de obras que van a acompañar a los primeros investigadores de campo sobre el terreno. Sobre Ch. F. M. Texier, véase MAsson, É. (1994): "Á la découverte des Hittites», Les dossiers d'archélogie, 193, pp. 2-11. También, GRAN-AYMERICH, È. (2001): Dictionnaire biographique d'archéologie, CNRS Éditions, Paris, pp. 657-658.

14 Sobre la persona, viajes y láminas de Pascal Coste y Eugène Flandin véase, ANDRÉ-SAlvini, B. y otros (1998) : Regards sur la ....... Perse antique. Le Blanc - Argentomagus, Blanc. El libro de viaje sería firmado por Flandin, E. y CosTE, P. (1851): Voyage en Perse de MM. Eugène Flandin, peintre et Pascal Coste, architecte pendant les années 1840 et 1841. Gide et Jules Baudry, Éditeurs, 2 vols.

15 LARSEN, M. T. (1996) : op. cit., p. 48-50. Absorbido primero por sus descubrimientos y luego por su carrera política y diplomática -entre otros destinos fue embajador en Madrid, en 1869-, A. H. Layard no publicaría hasta su vejez los recuerdos de sus aventuras juveniles en Irán e Iraq. Así, LAYARD, A. H. (1894): Early Adventures in Persia, Susiana, and Babylonia. Including a residence among the Bakhtiyari and other wild tribes before the discovery of Nineveh. John Murray, London.

16 Para la historia de las excavaciones francesas y británicas véanse PARROT, $\mathrm{A}$. (1946): op. cit.: LARSEN, M. T. (1996): op. cit.: FonTAN, E. y ChEvalieR, N. (eds.) (1994): De Khorsabad à Paris. La découverte des Assyrens. Réunion des Musées Nationaux, Paris.

17 Los cuadros 1 ( Acto III) y 2 (Acto IV) se desarrollan en los «Jardines Colgantes» de Babilonia, cuyas ruinas intentaron excavar entonces infructuosamente, los franceses de la misión de F. Fresnel (1852). Las puestas en escena fueron al principio fantasiosas, pero a medida que las excavaciones y los hallazgos avanzaron con el siglo, trajes y decorados fueron haciéndose más y más realistas. Sobre la ópera y sus circunstancias BATTA, A. y NeEF, S. (eds.) (1999) : op. cit., pp. 668-671.

18 Una versión española reciente en FlaUbERT, G. (1993): Viaje a Oriente (octubre, 1849 - junio, 1851). Edición y traducción de M. Gras Balaguer. Ediciones Cátedra, S. A., 1993. Una edición española de las cartas, FlaUberT, G. (1987): Cartas del Viaje a Oriente. Prólogo, traducción y notas de R. Cano Gaviria, Laertes, S. A. de Ediciones, Barcelona. Sobre el mismo viaje, son muy interesantes las páginas que le dedica en su estudio sobre Flaubert, WALL, G. (2003): Flaubert. Ediciones Paidós Ibérica, S. A., Barcelona, pp. 197-237. Y sobre Salambó, véanse sus pp. 297-310.

19 A mi entender, es excelente la biografía de Burton firmada por RICE, E. (1992) : El capitán Richard F. Burton. Ediciones Siruela, S. A., Madrid. Una versión española de su viaje a La Meca en Burton, R. F. (1989, 1990, 1993): Mi peregrinación a Medina y La Meca, 3 vols., Laertes, S. A., de Ediciones, Barcelona 1989 (vol. 1), 1990 (vol. 2) y 1993 (vol. 3).

${ }^{20}$ Gorshenina, Sv. y RAPIN, Cl. (2001): De Kaboul à Samarcande. Les archéologues en Asie Centrale. Gallimard, Paris, p. 28. Sobre las pautas de la ocupación rusa, GoRsHENINA, Sv. (2003): Explorateurs en Asie Centrale. Voyageurs et aventuriers de Marco Polo à Ella Maillart. Éditions Olizane, Genève, pp. 37-51.

21 En la Galería Tretiakov de Moscú se conservan además de la célebre Apoteosis de la guerra y escenas de la conquista rusa, una magnífica serie de lienzos de temática muy diversa dedicada al Turkestán. Así, Iovleva, L. (ed.) (2002): Tretyakov Gallery. Guide. State Tretyakov Gallery, Moscú, pp. 136-137. 


\section{Hasta los últimos confines}

22 La Sinfonía $\mathrm{n}^{\circ} 2$ Antar, Opus 9 de Nicolai Rimsky Korsakov, se compuso durante el año 1868, aunque se estrenó un año después bajo la dirección de Balakirev. Está inspirada en Las aventuras de 'Antar, epopeya de la literatura árabe ambientada en la Arabia preislámica: Rouger, G. (1998) : Las aventuras de 'Antar. Jose J. de Olañeta, Editor, Palma de Mallorca. Sobre la sinfonía y sus particularidades, véase TRANCHEFORT, F.-R. (dir.) (2002) : Guía de la música sinfónica. Alianza Editorial, S. A., Madrid, pp. 965-966.

${ }^{23}$ Hopkirk, P. (2001) : The Great Game. On Secret Service in High Asia.Oxford University Press, Oxford. Tambien véase, GorshenINA, Sv. (2003): op. cit., pp.44-49.

${ }_{24}$ Alexander Borodin compuso su poema sinfónico en 1880 , para celebrar el vigésimo quinto aniversario del zar Alejandro II. La música evoca la marcha de una caravana escoltada por soldados rusos, y mezcla melodías de ambos mundos en lo que Borodin quería símbolo de una nueva hermandad. La obra fue estrenada en San Petersburgo el 8 de abril del mismo año, bajo la dirección de N. Rimsky Korsakov, gozando de inmediato del favor popular y alcanzando pronto una gran difusión. Sobre A. Borodin y esta obra véase, TRANCHEFORT, F.-R. (dir.) (2002): op. cit. pp. 174-175.

${ }^{25}$ Gorshenina, Sv. (2003): op. cit. El libro trata sobre todo de los viajeros europeos no rusos -a los que cita sólo ocasionalmente-, orientando la cuestión de los centenares de viajeros rusos y su historia a la monumental obra de Olga V. Maslova, en cuatro volúmenes y publicada en ruso, titulada Obzor russkikh puteshestvij ekspedicij v Srednjuju Aziju (Materialy k bibliografii), Tashkent 1955, 1956, 1962 у 1971.

26 BAud, A., ForÊt, Ph. y Gorshenina, Sv. (2003): La Haute-Asie telle qu'ils l'ont vue. Explorateurs et scientifiques de 1820 à 1940. Éditions Olizane, Genève, pp. 58-61.

27 HEDDIN, S. (1991): Trois ans de lute dans les déserts d'Asie, 1894-1897. Éditions Pygmalion / Gérad Watelet, Paris.

${ }_{28}$ Pedraz Marcos, A. (2000: Quimeras de África. La Sociedad Española de Africanistas y colonialistas. El colonialismo español de finales del siglo XIX. Ediciones Polifemo, Madrid.

29 Dieulafoy, J. (1990): En mission chez les Immortales. Journal des fouilles de Suse, 1884-1886. Éditions Phoebus, Paris. Véase también, Gran-AYMERICH, E. et J. (1991): Jane Dieulafoy. Une vie d'homme, Éditions Perrin, Paris.

30 KRÖGER, J. (1995): «Zu Pferd mit Stift und Kamera. Die kleinasatische Reise von Friedrich Sarre", Museums Journal IV, 9, pp. 74-75.

31 PARKer, G. (1990): La revolución militar. Las innovaciones militares y el apogeo de Occidente, 1500-1800. Editorial Crítica, S. A., Barcelona.

${ }^{32}$ RitzenthaleR, C. (1987): L'École des Beaux-Arts du XIXe siécle. Les pompiers. Éditions Mayer, Paris, pp. 50-51, 306-307. 